\title{
CULTURAL ORIGINS OF PATTERNS OF PARTICIPATION IN MULTI-CULTURAL CLASSROOMS
}

\section{INTRODUCTION}

In order to accommodate the learning styles of students from a wide variety of cultural backgrounds, we need to consider the cultural origins of the patterns of participation displayed. In this chapter we report the detailed analysis of Overseas Educated (OSE) students' experience of first year university physiotherapy classes (utilizing a problem-based learning tutorial format) as an empirical example of teaching and learning in a multi-cultural setting. In particular, the analysis examines culturally-derived patterns of participation such as the Silent Participant, a pattern of participation that seems characteristic of OSE students from Asian classroom settings. In order to understand the inheritance of culturally-specific patterns of participation that students bring to multi-cultural classrooms, we examine classroom practices in eighth-grade mathematics classrooms contrasting these practices in three classrooms from Asia (Tokyo, Hong Kong and Shanghai) and with practices developed in three Western societies (San Diego, Berlin, and Melbourne). Our analysis suggests that there are distinct differences in patterns of participation both within Asian classrooms and Western classrooms. Thus teachers in multicultural classroom settings must avoid simplistic cultural typifications (e.g. Asian students considered as a homogeneous whole), while remaining sensitive to the differences in expectation and participation that students from different cultures inevitably bring to the multicultural classroom.

Classrooms are complex social and cultural settings, and research in such settings must reflect and accommodate that complexity. If we approach social settings (and the situations they frame) as multiply-constructed and open to multiple construal, then the methodology employed in their study must offer a voice to the several participants in these settings. This is particularly true when our interest is the cultural-specificity of practice. Research in such settings is inevitably shaped by the cultural orientation of the researcher(s). Every effort must be made to allow differences in cultural perspective to emerge in both the data collected and in the analysis undertaken. In all the research reported in this paper, post-lesson video-stimulated interviews offered classroom participants the opportunity to reconstruct for the researcher their actions in class, the motivations behind those actions, and the meanings they attributed to their actions and the actions of the teacher and their classmates. 
In this chapter, we conceive of patterns of participation, once institutionalized, as taking on the status of bodies of practice. A body of practice is an institutionalized conglomerate of related behaviours associated with a particular setting or profession with regularity of occurrence and consistency of form. Analysis of classroom data internationally is utilized to demonstrate the coconstructed nature of these patterns of participation and consequently of this practice. Rather than progressively increasing the competence of their participation in a culturally or socially pre-determined practice (e.g. Lave \& Wenger, 1991), this conception of the origins of practice accords significant agency (however constrained by institutional or cultural norms) to the participants to shape their particular pattern of participation and thereby to influence the nature of that practice. Wenger's more recent writing (Wenger, 1998) assigns significantly greater agency to the participants in a practice and our analysis provides examples of how that agency is enacted.

It is necessary to situate classroom practice in the context of a theory of pedagogy in multicultural settings. As Greeno (1997) observed, "Methods of instruction are not only instruments for acquiring skills; they also are practices in which students learn to participate" (p. 9). From this perspective, the patterns of participation documented in either first-year physiotherapy classes or eighth-grade mathematics classes embody not just pedagogical practices as means to the educational goals of the classroom but valued socio-cultural practices from which the participants' learning is constituted.

Individuals function as cultural works in progress (Eisenhart, 2001) who carry multiple cultural affiliations with them, and who constantly respond to and reshape their cultural guidelines through engagement with the cultures around them. While individuals carry learned preferences for cultural behaviours that they are more comfortable enacting, their attachment to these behaviours will vary within different cultural contexts. No two individuals are likely to negotiate an unfamiliar cultural landscape the same way, so that cultural engagement is as much about diversity and complexity as it is about a shared understanding of learned guidelines (or local cultural norms). Related to this point, we suggest that any assumption of Asian culture as mono-cultural is problematic and ignores the diversity and complexity inherent in any student group.

In reporting the analysis of problem-based learning (PBL) tutorials in physiotherapy, we describe how overseas-edicated students experience and respond to an unfamiliar learning context that requires public display of dialogic and collaborative skills. The learning context obliged students to shift to a stance as autonomous learners, responsible for peer and self-education. The documented practices were a consequence of the congruence and dissonance between the PBL instructional agenda and students' own culturally-derived patterns of participation. The tension that is fundamental to the multicultural classroom (and curriculum) arises because the social practices that mediate the students' learning constitute in themselves an essential component of that learning, and these to-be-learned social practices can be at odds with the culturally-grounded learning preferences and patterns of participation of the students. Accepting this tension as inevitable, the pedagogical challenge is to honour the cultural inclinations of individual students towards particular patterns of participation, while progressively initiating the students into classroom practices that themselves model essential curricular elements. Examples of such practices illustrated in this paper include particular forms of socially-enacted argumentation valued by the mathematics community and discursive practices central to the clinical reasoning valued by the physiotherapy community.

CULTURE

Introduction to notions of culture

Understandings of the notion of culture as a categorizing device are complex controversial and repeatedly being reconstructed in the anthropological, psychological, sociological and educational literature. Initially developed as a tool by anthropologists for understanding differences between groups, it has subsequently been appropriated by other disciplines such as educational psychology and sociology, to develop an understanding of the learned principles that guide the social choices of individuals and group members. Multiple definitions exist which categorize culture as a cognitive, structural and/or symbolic system (Bennett, 1998; Chang \& Holt, 1993; Forte, 1999; Geertz, 1973; Hall 1989; Hofstede 1994). Eisenchlas and Trevaskes (2003) noted that in a review completed in 1952, 164 definitions of culture were found in the anthropological literature alone, a number that would have increased significantly with time and across disciplines.

Culture was conceptualized by Gudykinst, Ting-Toomey and Chua (1988) as a "script or schema shared by a large group of people" (p. 30) and by Hofstede (1994) as the "(...) mental software learned throughout a lifetime and dependent on the group of people and the shared values surrounding the person. It is the collective programming of the mind which distinguishes the members of one group or category of people from another" (p. 5). In the past, typically broad definitions of cultural groupings were categorized under ethnographic variables such as ethnicity, nationality, religion, and language; demographic variables such as age, gender and place of residence; and more socially constructed variables such as social, educational and economic groupings (Brislin \& Yoshida, 1993). Within all early conceptualizations of culture, emphasis was on learning from an early age about meaning systems, with the establishment of fundamental values that influence patterns of thinking, feeling and acting.

The pervasive nature of culture in all activities is characterized in the following quote:

[Culture is] what ever it is one has to know in order to operate successfully, and in a manner acceptable to the members of a given society of things that people have in interpreting. Culture consists of guides or standards for deciding what is, for 
deciding what one feels about it, for deciding what to do about it, and for deciding how to go about doing it. It consists of shared ideas, rules and meaning, or a code, mainly submerged beneath consciousness, which enables individuals within a community to communicate, live, work and anticipate and interpret behaviour. Culture informs, influences and shapes fundamental beliefs and values and thereby shapes expectations, attitudes, behaviours and practices. (Goodenough, 1964, cited in Minas \& Klimidis, 1994, p. 139)

Culture has therefore been conceptualized as the learned consciousness that shapes what we see and how we interpret the world around us, as well as what we do. It includes the rules of culture as well as the tools of culture, the latter referring to symbols and social practices that are publicly available (Forte, 1999). In this view, culture is the lens through which we interpret the world around us.

This concept of guidelines, codes, fundamental beliefs and values are often portrayed as an inflexible system, which is powerful, deep seated and collective (Hall \& Hall, 1990; Hofstede, 1994; Miller, 1999). It is not uncommon to hear of culture being discussed as a great divide between people, and as limiting an individual's ability to cope outside their own cultural boundaries. In some instances, when behaviours are labelled as cultural, the implication is that the individual is somehow locked into the behaviour, without the freedom to negotiate and to reshape meanings in an unfamiliar culture. This typification of culture appears to be commonly operating in the health science literature whenever culture is mentioned. The risk here is that culture is used as a label or stereotype, where all individuals are seen to believe and behave according to rigid principles of practice. It is our contention that this conception of culture does not reflect the true complexity of individuals' interaction in the social world.

An interesting problematic in the study of culture is that substantial literature describing cultural patterns has been developed by outsiders to the culture. For example, descriptions of student behaviour in Asian cultures are often provided by Western analysis and therefore could be criticized as not representing a lived understanding of the cultural values, and consequently as being open to error and misunderstandings. There is a growing body of literature from Asian scholars or Western trained Asian scholars working to clarify cultural understandings as insiders or natives of the culture (Ho, 1993, 1995, 1998; Leung, 2001; TingToomey, 1999). This body of literature has reconstructed previously identified cultural issues such as face, and highlighted less familiar cultural understandings such as Yuan which is described as secondary causation and the influence of context on behaviour. These insider insights are providing more subtle readings of culturally embedded beliefs. Further, authors from culture that have been interpreted and analysed by cultural outsiders have been critical of interpretations of their belief systems and understandings and challenge the right of outsiders to interpret their cultural understandings. Chang and Holt, (1993) pointed out that "the key to understanding the broader conceptualizations of detecting the meanings of a given culture lies in the realization that we can never get direct access to what is in the native's mind" (p. 31). It might also be said, however, that the very familiarity of cultural norms renders them invisible to insiders and that the identification and understanding of cultural practice is best achieved through a partnership between outsiders, who are more likely to find a practice distinctive, and insiders, who are better able to interpret the meaning of that practice. Our own work has provided many examples of the value of such partnerships (e.g. Clarke Emanuelsson, Jablonsky, \& Mok, 2006; Li, 2007).

Challenging the notion of culture as a category

The assumption that cultural values are fixed and rigid rules that exist for al members of a social group has been criticized as a monolithic and narrow view of how individuals operate within a social group (Eisenhart, 2001). This view of culture as an explicit, homogeneous and distinctive collective (Adams \& Markus, $2001)$ has been problematized. There is a concern that essentializing and stereotyping occurs when we resort to standard cultural categorizations (Eisenhart, 2001).

One conceptualization of culture that is less rigid is one in which individuals internalize its rules and nuances to a different extent, and act out varying attachment to cultural values. Further, these values are constantly being reorganized in response to the context, and to the degree to which the meanings in the context are explicit. Internalization of culture can become further complicated when individuals spend significant time in or are exposed to complex new cultural environments The extent to which the individual reflects the values of their primary culture as well as the degree to which they have absorbed secondary cultural influences their individual cultural mix. This may be especially true of migrant-origin students who have spent a significant period of time in Australia, and who, as young adults are likely to have accepted and incorporated Australian values into their cultural behaviour. Geertz (1973) wrote that the problem with cultural analysis was in locating overlaps and gaps, gulfs as well as bridges.

The concept of individuals producing culture is a major shift in the conceptualisation of culture. Eisenhart (200I) describes one understanding of culture as:

a set of symbolic and material forms, affected but not determined by history and structure, actively appropriated or produced in groups to bring order and satisfaction to experiences. In consequence, culture includes both enabling and disabling dimensions, both reproductive and transformative possibilities for those who produce and live by it. (p. 213)

In this view, culture and the individuals who live it are a work in progress. Theories on identity formation and personality theory are gaining prominence in examining difference in social engagement between groups (Adams \& Markus, 2001 ). For example, Hermans (2001) conceived "self and culture as a multiplicity of positions among which dialogical relationships can be established... culture and selves are seen as moving and mixing and as increasingly sensitive to travel and 
translocality" (p. 243). Here we have culture as self-inclusive and self as culture inclusive (Hermans, 2001).

Culture is seen as a more dynamic and complex process that responds to power dynamics, context and priorities that may be flexible and shifting. It is viewed as more ephemeral and dependent on context, and negotiating culture is seen as a creative process (Eisenhart, 2001). Individuals, therefore, can and do negotiate both familiar and unfamiliar cultures in an agentical manner, developing cultural identities as they progress. However, despite this acknowledged agency, individuals are not entirely free to take any identity they wish, as social assumptions and dialectical positioning will influence how the individual is allowed to construct their identities (Adams and Markus, 2001). This is inclusive of cultural patterns adopted and displayed by individuals.

The main message here is that cultural identities are constantly adjusting and 'not frozen for inspection' (Rosaldo, 1993, cited in Spack, 1997). It is increasingly recognized that cultures are hybrid and heterogeneous, that individuals carry multiple cultural influences, and that the categorization of individuals within a single cultural frame is less useful for a younger generation who are less constrained by history and isolation. Another view of culture is as 'implicit and explicit patterns that are (often) associated with groups', with individuals 'engaging with patterns' rather than having limited membership of a group (Adams \& Markus, 2001). Here the notion of multiplicity of cultural influences becomes important. Individuals have some choice in the cultures they expose themselves to and the value systems they engage with. That is, they construct identity, not just synthesize identity (Adams \& Markus, 2001). Exposure to multiple cultures makes us multi-cultural as individuals, a unique work in progress, rather than categories of individuals who follow the same rules under the same conditions.

We view culture as less about a rigid categorization between groups and more about shared patterns of understandings that individuals (teachers and students) use to develop their personal codes for interpreting what is occurring around them. No two individuals from the same culture will respond the same way to the same stimulus. Personality and personal history each have their place, and any analysis must be sensitive to cultural diversity within each context.

\section{Classroom culture}

Since culture is framed as pervading all social contexts, it can be seen to exist in the classroom context. Classroom culture is the context in which students build their understanding of the cognitive, behavioural, affective and communicative demands placed on them. There is a literature that suggests that classroom cultures have a profound effect on student learning and it seems likely that this effect would hold and maybe even be heightened for students who are learning in a new and novel culture.

The term classroom culture is in common usage in the education literature, but is often used without clarification of its meaning. There is an assumption of a shared understanding of the meaning of the term. As with the concept of culture itself, there is room for multiple conceptualizations of this construct. Marilyn Nickson's (1992) conceptualization of classroom culture is closest to our usage:

The invisible and apparently shared meaning that teachers and pupils bring to the classroom and that governs their interaction in it ... It includes the knowledge, beliefs and values that are held by the actors in the setting ... unseen beliefs and values, of both student and teacher. (Nickson, 1992, p. 102)

The literature suggests that classroom culture is based on the cultural baggage of the teacher/tutor and/or the student participants, predominantly drawing from the mores of the dominant cultural group. It is seen as evolving and responsive to input from its participants (O'Brien, 1993). It has been argued that the classroom culture is not always explicit to students, especially to those who are undergoing socialisation into a new classroom culture (Garner, 1992). This argument is strongest for overseas-educated students whose own background culture and whose experiences of classroom cultures may be vastly different from the Australian PBL classroom culture. Ballard (1995) noted that culture "is seldom made explicit but must be acquired by imitation, osmosis and (often) chance". Additionally, students are confronted by "conflicting, but seldom coherently articulated demands and models of appropriate behaviour" (p. 107). The suggestion here is that the classroom culture may not be visible to all students (especially overseas educated (OSE) students) who participate in it.

\section{Cultural literacy}

The concept of cultural literacy is useful for framing how individuals read and respond to the classroom culture. Cultural literacy has been defined as knowledge and understanding of meaning systems and a way to negotiate those meaning systems appropriately in different cultural contexts (Schirato \& Yell, 2000). This concept can be framed in terms of reading what is important in different situations; in being able to sum up the priorities of the time, and then acting in a way that best suits the situation. It also includes the ability to recognize the legitimate choices available in a social context.

Individuals have different levels of cultural literacy in any social context. Those familiar with a cultural context can display a more sophisticated literacy, while those who are new to the culture, may feel illiterate. A high level of cultural literacy in a classroom would involve understanding the rules of the classroom culture, both explicit and implicit. In classrooms, it is about accurately reading the expectation, obligations and appropriateness of one's behaviour, with all its nuances.

Our position is that there are multiple cultural literacies required in any classroom. All students bring their own literacies to the classroom that they use to make sense of the cultural clues available. In this research context, students needed to engage in many layers of culture: Australian, institutional, student, youth and the classroom context itself. One issue that has been raised in the literature is that 
culture in the short term, such as in new classroom environments, cannot be learned solely via exposure or osmosis, but needs to be taught explicitly (Eisenchlas \& Trevaskes, 2003)

\section{Contrasting learning styles}

There is an extensive literature devoted to exploring the differences between educational cultures in Confucian-heritage and Western contexts. Attention is typically directed to differences in values related to learning, classroom cultures and cultural preferences for different classroom behaviours (examples include Hofstede, 1986; Jones, 1999). The literature ranges from anecdotal descriptions of differences in learning behaviours and social choices, to more detailed research reports. The major part of the published research literature appears to be dominated by questionnaire data, with less emerging from qualitative studies. While some of the research is convincing, this cannot be claimed for all literature in this area. The majority conclusion however, points to marked differences in social, cognitive, affective and behavioural domains, which indicates major differences that are likely to influence the learning experiences of OSE in an unfamiliar classroom culture (Gupta, 2001). In this chapter we use the example of Asian students learning physiotherapy practice in a small group collaborative learning context (problem-based learning, [PBL]) in an Australian tertiary setting.

In relation to the issue of simplistic characterisations of Asian classrooms, Khoo (2003) completed a comprehensive literature review that examined issues inherent in the implementation of Problem-Based Learning (PBL) in Asian medical schools, searching publications from conferences and journals on the Asian PBL experience. Arguing that PBL requires certain attitudes and characteristics in learners that may be problematic for students from non-Western cultural backgrounds, Khoo (2003) identified what has been characterized in the literature as Asian cultural attitudes. He identified seven Asian attitudes that are viewed as incompatible with PBL requirements. These were:

- Fear of confrontation with authority;

- Distaste for open criticism of authority;

- Compulsion of dependency and respect for authority;

- Confucian socialization which requires the individual not to be outspoken;

- Lack of passion for studies;

- Lack of ability/motivation to ask questions; and

- Low participation in class discussions. (Khoo, 2003, p. 402)

One striking theme in the literature is the characterization of the Confucianheritage students as engaging in less than ideal learning strategies and classroom behaviours. Students are viewed as surface learners, devoted to rote learning, and with little intrinsic motivation for learning. Curriculum is viewed as contentoriented and examination-driven and teaching as traditional and old-fashioned (Leung, 2001). Asian students are seen as resorting to unproductive learning strategies such as memorizing in preference to understanding of complex texts (Ballard, 1995; Burns, 1991; Kennedy, 2002). Further, students have been portrayed as overly dependent on their teachers; having attachment to the right answer; a preference for concrete rather than abstract knowledge; a tendency to plagiarizing and considerable difficulty engaging in critical reasoning (Ballard, 1995; Ninnes, Aitchinson, \& Kolas 1999; Samuelowicz, 1987). Ballard (1995) notes "there is greater emphasis on the reproductive approach with respect paid to teachers, to age, to traditional wisdom, and with rewards given for accurate repetition and imitation" (p. 109). In Au and Enthwistles' (1999) words "memorisation becomes a well-established and overt way for Chinese students to show their effort and their respect for a teacher's knowledge, and to achieve academic success, where the assessment requires only the reproduction of what has been taught" (p. 11).

Poor classroom participation, especially in tutorial settings has also been associated with Confucian-heritage students, as they are "untrained to ask critical questions and raise alternative opinions to those of the lecturers or older students' (Ballard, 1995). Students are seen to lack analytical and critical skills as they are trained "not to question, not to reflect, not to think or act independently, and not to organize their ideas in a logical and linear manner" (Jones, 1999, p. 3). Students' lack of confidence in using their own words to explain material is seen as further compounding this problem (Au \& Enthwistle, 1999). The majority of anecdotal and descriptive reports therefore provide a view of Confucian-heritage cultures as exam-orientated, achievement orientated and with a preference for rote-learning (Li, 2007; Wong, 2004).

The main message from more research-based reports on cross-cultural learning experiences is that students from different cultures approached their learning differently. Hofstede's work on learning differences between cultural groups has been viewed as seminal to this body of literature. His often-quoted paper titled Cultural differences in teaching and learning (Hofstede, 1986) is one of the most marked examples of the characterizing of teaching practices as polar opposites between cultures. Hofstede's conceptualisation of cultures as differing along four dimensions: collectivist and individualists; low and high power distance; weak and strong uncertainty avoidance; and feminine and masculine societies is expanded to include teacher and students' preferences for interactions. For example, if a culture was predominantly high power distance (Japan), its teaching practices were markedly different to cultures that are low power distance (Australia). Since Australia is situated very differently from the majority of the Confucian-heritage cultures on all four dimensions, the theoretical contrast between classroom cultures is substantial. Classroom differences along these four dimensions have been reinforced in several publications (examples include Dadkhah, Harizuka \& Mandal, 1999; Niles, 1998). Some of these documented differences are listed in Table 1 . 
Table l. Comparison of Asian and Australia learning styles

\begin{tabular}{ll}
\hline Asian & Australian \\
\hline $\begin{array}{l}\text { Rote learning is common } \\
\text { Non critical reception of } \\
\text { information }\end{array}$ & $\begin{array}{l}\text { Evaluative learning is preferred } \\
\text { Critical thought is expected }\end{array}$ \\
$\begin{array}{l}\text { Students work hard to learn } \\
\text { everything }\end{array}$ & $\begin{array}{l}\text { Students selectively learn the central concepts as well } \\
\text { as detail }\end{array}$ \\
$\begin{array}{l}\text { Students are inclined to seek } \\
\text { clarification }\end{array}$ & $\begin{array}{l}\text { Students are willing to seek assistance as part of the } \\
\text { learning process }\end{array}$ \\
Few initiatives are taken & Independent learning and research are rewarded \\
$\begin{array}{l}\text { A willingness to accept one } \\
\text { interpretation }\end{array}$ & $\begin{array}{l}\text { Students are encouraged to apply general principles to } \\
\text { specific situations and to test various interpretations }\end{array}$ \\
$\begin{array}{l}\text { Overall concepts are seen as } \\
\text { important to understanding }\end{array}$ & $\begin{array}{l}\text { Analytical thinking is encouraged. Students are } \\
\text { expected to support opinions with logical argument. }\end{array}$ \\
\hline
\end{tabular}

(Adapted from Phillips, 1990, cited in Ramburuth, 2001, p. 4).

Laboratory research has been published on the cognitive differences between East Asian Chinese (from Korea, Hong Kong, China and Japan) and American students (Nisbett, Peng, Choi, \& Norenzayan, 2001; Norenzayan, Nisbett, Smith, \& $\mathrm{Kim}, 2002$ ). Marked differences in cognition, especially in relation to problem solving and reasoning have been repeatedly identified. Nisbett and associates have concluded that the ontology and epistemology are deeply and fundamentally different as a result of a long history of difference in philosophy between Greek (Western) and Chinese (East-Asian) thinking. They contrasted the Greek sense of personal agency with the Chinese sense of social reciprocal obligation or collective agency, and associated this contrast with a consequent difference in learning behaviours.

Nisbett and associates (2001) hypothesized that a major consequence of the Western preference for analytical thinking and the Chinese preference for holistic thinking is a different approach to problem solving and reasoning. East Asian students showed 'attention to the context or field as a whole, a concern with relationships among objects and between the fields and the object, and a preference for intuitive approaches, as well as a "dialectical" reasoning, which seeks the "middle-way" between conflicting propositions' (Norenzayan et al., 2002). Dialectical reasoning has been described as 'a compromise approach, retaining basic elements of opposing perspectives by seeking a "middle way" (Peng \& Nisbett, 1999). They have argued that while East Asian students have the same degree of ability for abstract arguments as Western students, they have difficulty decontextualizing the context of an argument from its logical structure (Norenzayn et al., 2002). It was noted that one style of reasoning is not superior to the other, since each approach is likely to cause errors in different situations.
Differences in the social dimension of cultural practices have also been reported, with the view that Confucian-heritage students are more preoccupied with social harmony due to their coming from collectivist cultures (Eisenchlas \& Trevaskes, 2003; Harris \& Nibler, 1998;). This contrast between consensus-based decision making with the preference for adversarial debate in the West has been highlighted (Nisbett et al., 2001). Research has examined how students work within groups and concluded that differences existed based on the ingroup status of group members. Harris and Nibler (1998) looked closely at how either American or Hong Kong Chinese students managed group problem solving challenges. Differences were found dependent on whether students were working with their ingroup/friendship group compared to minimal/acquaintance groups. Chinese students were found to be more effective in their ingroup in contrast to the American students. Interestingly, the Chinese group also considered their discussion more intense and conflict ridden than the U.S. participants did. The authors argued that collectivist groups were more occupied with social issues and the relationship between group members so that the successful completion of the task would be less important than "the conciliatory image portrayed to other group members" (Harris \& Nibler, 1998). Interestingly, they found that although students used subtle and indirect terminology in their in-group, some did become more vocal and loudly spoken on occasions, while indicating that they were careful not to offend anyone and cause any group member to lose face.

The issue of the difference between in and out groups is especially relevant in the consideration of the social dimensions of how students do groupwork. To quote directly from Gudykunst (1997) on this issue: "people in individualistic culture tend to be universalistic and apply the same value standards to all. People in collectivistic cultures, in contrast, tend to be particularistic and apply different value standards to ingroups and outgroups" (p. 327). This suggests that viewing oneself as an in-group member in groupwork (e.g. PBL tutorials) may be of more importance to OSE students than to local students in this study.

Another accepted difference in the literature is the valuing of effort rather than ability as more responsible for academic success in Asian countries ( $\mathrm{Au} \&$ Enthwistle, 1999; Wong, 2004). It is this notion of effort over an intrinsic talent for and enjoyment of learning that Leung (2001) has highlighted when he referred to East Asian students deriving pleasure from the challenge of study and the "contentedness derived from having put in hard work and arriving at a deep knowledge of the subject" (p. 4). This view of motivation contrasts strongly with the epistemic curiosity expected in Western classrooms.

Despite some of the limitations in the literature in this area, the consistent finding is that Confucian-heritage students differ in terms of approaches to learning from what is valued in Western learning contexts. There appear to be well entrenched myths on the surface learning practices of Confucian-heritage students, and it is our experience that these myths often operate at the classroom level, where teachers accept them as established facts and behavioural norms. 


\section{METHODOLOGY}

The research studies

Both of the studies that provide the focus of this paper employed classroom videotaping and post-lesson video-stimulated interviews. With regard to both classroom videotaping and the post-lesson interviews, the principles governing data collection were the minimization of atypical classroom activity (caused by the data collection activity) and the maximization of respondent control in the interview context. To achieve this, each videotaped lesson sequence was preceded by a familiarization period in which all aspects of data collection were conducted until the teacher indicated that the class was functioning as normally as might reasonably be expected. In interviews, the location of control of the video player with the student ensured that the reconstructive accounts focused primarily on the student's parsing of the lesson (that is, the student's perception of the key structural elements in the lesson). Only after the student's selection of significant events had been exhausted did the interviewer ask for reconstructive accounts of other events of interest to the research team. Documentation of the participant's perspective (learner or teacher) remained the priority.

Video-stimulated recall interviews are conversations based on videotaped data of classroom action. The interview protocol required students to reconstruct classroom events as captured on these videotapes. The interview process associated with video-stimulated recall relied on minimal prompts to encourage students to describe their perception of key events, the thinking behind their behaviours, the meanings they gave to the classroom activities, the feelings behind their interpretations and their reactions to what was occurring. This technique had been used previously to collect insights on "the individual's construal of those (classroom) events, the memories invoked, and the constructions which arise as a consequence" (Clarke, 1998). In the case of the PBL study, it was selected as a research technique because it situated and gave context to students' reports of their PBL experiences, and because it had the potential to give a richer and more visible account of how PBL classroom activity shaped understanding of PBL.

\section{The PBL study}

A hybrid PBL program was used to cover curriculum content in the first year program of a School of Physiotherapy at a University in Australia. A hybrid program supplements PBL tutorials with other modes of teaching, such as lectures and practical classes. In PBL, students work in small groups to construct new knowledge from a messy clinical problem. Students go through a systematic process to identify: I) what they know about the problem, 2) what they do not know about the problem, and 3) what they need to research to understand more about the problem. They spend five hours in three separate sessions working together on the problem. Between sessions they are requested to work independently to research the learning issues they identify during the group sessions

Typically the PBL setting was a smallish tutorial room with nine to eleven people seated in a round table formation. Commonly the group comprized one tutor, one OSE student and nine local students. Food and drinks were allowed in the classroom and were often shared during the PBL sessions. When PBL worked well, the sessions were highly verbal, with periods of animated discussion questions, challenges, agreement and disagreement, debate, explanations and identification of knowledge gaps. There were also periods of hesitation, silence and frustration. One group member typically acted as chairperson and one as group scribe, recording each student's contribution on a white board. On occasions there were questions and calls for clarification from other group members and the tutor. In some classes, the tutor was dominant, directing questions to students and raising issues for discussion. In other classes, tutors spoke less frequently and students appeared to be controlling their progress.

The aim in the PBL study was to gather on videotape the complexity of PBL practice and a representative range of activities and group dynamics that typically occurred over one PBL problem. It was decided to videotape the first and last two hours of the process as a method of collecting maximal PBL tutorial action. The one-hour middle sessions' were typically review sessions, and each group appeared to be idiosyncratic in how they ran these sessions. The middle sessions were felt to be less revealing of PBL practice, and four hours of video data per problem was thought to provide an adequate representation of PBL tutorial activity. The videotaping of PBL tutorials employed two cameras and a one-semester familiarisation period allowed students to adjust to both PBL and the presence of the video cameras.

The learner's perspective study

Data collection in the learner's perspective study (LPS) involved a three-camera approach (teacher camera, student camera, whole class camera) that included the onsite mixing of the teacher and student camera images into a split-screen video record that was then used to stimulate participant reconstructive accounts of classroom events. Data generation was undertaken in the well-taught eighth grade mathernatics classrooms of three teachers in each of the twelve participating countries (Australia, China, the Czech Republic, Germany, Israel, Japan, Korea, The Philippines, Singapore, South Africa, Sweden and the USA). This combination of countries provides examples of Western and Asian educational traditions, and represents culturally diverse countries.

Each participating country used the same research design to collect videotaped classroom data for at least ten consecutive math lessons and post-lesson videostimulated interviews with at least twenty students in each of three participating 8th grade classrooms. The three mathematics teachers in each country were identified

Currently these one-hour sessions are not supervised by PBL tutors and are used by students to discuss the progress they are making in their research 
for their locally-defined teaching competence and for their situation in demographically diverse government schools in major urban settings. The three lesson sequences were spread across the academic year in order to gain maximum diversity of local curricular content. In a major component of the post-lesson student interviews, in which a split-screen video record was used as stimulus for student reconstructions of classroom events, students were given control of the video replay and asked to identify and comment upon classroom events of personal importance. Each teacher was interviewed at least three times using a similar protocol.

The intention in both studies was to allow students to identify their own priorities. Each interview always started with an explanation of the objective of the interview and the student's role in guiding the process. The student was given the remote control so that they had control over what they chose to discuss and what they elected to ignore. Students were asked to fast forward the tape to a point where the classroom interaction was important (LPS) or meaningful (PBL) to them, at which time they should slow the tape down to normal speed. They could then discuss why they had chosen that particular episode and what they were doing, thinking and feeling at the time. Once we had finished discussing the episode, the students would again fast-forward to the next point of interest. The majority of students managed the video-stimulated recall process very well, moving effectively from key event to key event. Students were interviewed about their reconstruction of the video data as soon as was practical, allowing for their timetable. The majority of interviews were completed on the same day as videotaping and lasted approximately one hour.

There were several advantages to this interview method as students focused their accounts on real events and used these events to highlight what they saw as meaningful in their classroom or tutorial experiences. The data generation process provided clear visual images of what was occurring in the classroom, as well as insight into what students valued and how they interpreted classroom events. Importantly, for quiet students, it made available clear triggers on which the interviewer could base her questions and offered a shared reference point for conversation. The video data also provided a very useful permanent record for later analysis of classroom interaction.

\section{THE SILENT PARTICIPANT}

\section{Silent Participants}

Video data from the PBL study indicated that the OSE students could be viewed as Silent Participants who contributed infrequently in PBL tutorials. We define the Silent Participant as a group member who speaks minimally during PBL tutorial sessions. They limit the length of their utterances, do not ask questions, make small talk, or enter discussion or debates that expanded on group dialogue. The video data findings were reinforced in interviews with students and tutors typically identifying the OSE students as amongst the quietest members of their group. However, they were always present during the session, responded when prompted by the tutor or other students, and were prepared to research and present (not always orally) the results of their research. In effect, the Silent Participant limited their verbal participation to the minimal PBL obligation.

Two points need to be highlighted here. Firstly, the pattern of silent participation was not exclusive to OSE students. A number of local students could be identified as Silent Participants from video and interview data. Secondly, whilst the behaviour of Silent Participants appeared the same, the experiences of these students and the reasons they offered for their modes of participation were very diverse. A key finding of the following analysis is that students did not stay silent for the same reasons or read the same constraints into verbal participation. Also, it should be remembered that in this context, it was common to have only one OSE student per PBL group. This pattern of silent participation may not have been identified if there had been more OSE students participating within a group.

Understanding the extent to which dialogue is central to PBL is key to understanding the nature of silent participation in PBL tutorials. In this context, three reasons have been identified as to why all students are encouraged to verbally contribute in PBL tutorials: 1) elaboration is thought to be fundamental to learning, 2) students need to develop communication skills prior to their entry to the clinical domain, and 3) concern for equity requires all students to share the burden of learning.

It has been argued that students need to articulate what they are learning and that students who cannot verbalize content knowledge are not learning in a way that is conscious and under their control. In theory, students learn from their own elaborations and from the elaborations of their peers, with the opportunity to learn more content knowledge in greater depth. The importance of student elaborations of content knowledge has been demonstrated in studies in different educational settings. For example, Clarke (2001) reported this as the central finding of an extensive analysis of videotape data of students in Australian mathematics and science classrooms. However, the point will also be made in Section 5 that some Asian classrooms do not encourage student articulation. This suggests that PBL as a pedagogy is predicated on a different theory of learning than that assumed in many Asian classrooms. Certainly, elaboration of knowledge is a skill not equally developed by all students, and in theory, PBL provides both local and OSE students with the opportunity to develop this skill in a safe small group environment.

An additional and profound advantage to students' public elaborations is that their depth of understanding and clinical reasoning is made visible to tutors who can better hear the quality and accuracy of students' learning, and better scaffold this learning. The value of elaboration in PBL may lie as much in building the tutor's confidence that students are reaching curriculum objectives as with building students' confidence that they are learning. It will be argued on the basis of LPS data that the role of student-initiated articulation in PBL pedagogy contravenes several of the tenets of accepted practice in the classrooms with which many Asian 
OSE students are familiar. The relative contributions of teacher/tutor and students to the generation of new knowledge challenge OSE students' assumptions about the role of the teacher/tutor. This may be especially true in this context where tutors avoided giving students feedback on the accuracy of their content knowledge and reasoning.

Also of relevance is the tutors' view (all tutors were physiotherapists) that failure to communicate in PBL is likely to indicate an inability to communicate in future clinical practice. Students' ability to find their voice in PBL was seen as related to their ability to find their voice in the clinical domain. There is intuitive appeal in the proposition that students who are competent and confident in their communication skills in discussing clinical issues in PBL will be competent and confident in communicating with patients and colleagues in the real world of clinical health care. However, it must be acknowledged that there is no direct evidence that students who do not communicate in the PBL forum will be incompetent in communicating in the clinical domain. Further, since PBL tutorials bear little social resemblance to that of the clinical setting, this connection may be more tenuous and less significant than is commonly accepted.

Students' perception that PBL brings with it a large workload has been documented in the literature (Azer, 2001). However, less is known about how students' perceive the possibility of distributing this workload evenly across all group members. In this study, no local students ever complained that OSE students were having a free ride at the expense of other harder-working students. However, the need to keep expectations consistent for local and OSE students is one that has been voiced by tutors, and the risk of seeing one cohort of students as passengers who learn from, but do not contribute to the group's learning, may be problematic in some circumstances.

There is no evidence that silent students do not learn from the PBL process. The choice to be a Silent Participant is not inevitably linked to a passive form of participation and a failure to learn (Blue, Stratton, Donnelly, Nash, \& Schwartz, 1998; Chalmers \& Volet, 1997; Graham, 1996). Therefore silent participation can be viewed as one way to learn in the PBL context, and it can be argued that both the content knowledge and skills required in PBL can be learned from listening and that students can contribute to PBL by bringing with them well-researched material that they share with their group. Theoretically students can learn by listening to others reasoning, debating and questioning each other and elaborating on physiotherapy content knowledge. However, the extent to which OSE students can follow the group's progress through the messy and complex PBL problems and learn essential content knowledge as Silent Participants does need further investigation. In this study, it appeared that some OSE students struggled to keep pace with the discussion and that learning was predominantly left for outside the PBL classroom and a more private learning setting.

The emphasis in PBL on verbal participation is partly driven by a belief that all students should and can contribute to knowledge generation. However, it is possible that the obligation to contribute verbally, and in a second language, may constrain students to a less effective mode of participation, and so inhibit student learning. Caution is also needed in viewing public elaboration as the only reflection of active engagement in learning in PBL. We are a long way from knowing how students engage with learning in PBL, and there was evidence in this study that OSE students were deeply engaged with the PBL process and were actively and independently searching for meaning in the PBL material.

Whatever the ground for arguing the importance or otherwise of verbal participation by OSE students, a key issue is whether OSE students had a genuine choice as to their mode of participation. The evidence was that most of the OSE students in this study felt silenced by the PBL process and by their culturally embedded preference for listening to learn. Other factors such as language and cultural literacy related to communicating in an Australian classroom context also had an influence in keeping OSE students silent. In this cohort of OSE students, more students indicated that they would have liked to speak (if given a choice) than indicated a preference not to speak (if given a choice) in PBL tutorials (Remedios, Clarke, \& Hawthorne, 2008).

\section{The PBL classroom culture: Intended and enacted}

The first level of analysis of the PBL classroom culture is based on the operating principles and values designed by the faculty at the university to be used in the practice and structure of the PBL sessions. Five operating values that emerged as most challenging to the OSE students in this study were:

1. Dialogue as a learning tool

2. Debate and discussion as an essential device for deeper learning

3. Students as self-directed learners responsible for defining, searching for, and elaborating on content knowledge

4. Students as more visible than teachers in the PBL process; and

5. The importance of collaboration and inclusion of all students in the PBL process.

In this study, all students' interviewed indicated an awareness of these values, although their interpretation varied as to how these values were enacted.

These five values have all been previously discussed in the literature, and have all been described as fundamental to PBL practice (see for example Amos \& White, 1998; Edens, 2000). Importantly, faculty and tutors' viewed these values as fundamental principles of PBL practice. In effect, these were seen as essential elements to what makes PBL an effective educational strategy for preparing future clinicians. Although likely to feature in most PBL contexts, the enactment of these values may vary between settings and the classroom cultures that subsequently develop may be different. For example, Dixon, Lam, Lam and Ho (1997) described PBL tutorials in Hong Kong, where tutors dominated the tutorials and where debate and discussion were less obvious features. 
The second level of analysis represents how students perceived the key obligations of PBL practice. These five obligations developed as a consequence of the way the institution enacted their policy in tutorials. These obligations were to:

1. Contribute orally

2. Question/challenge others

3. Accept that content authority resides with self and peers

4. Learn publicly

5. Work with others as a social unit

All students were required to respond to these obligations appropriately. According to the literature, these five obligations are in direct contrast to the classroom practices of Confucian-heritage countries. This apparent tension is supported by the OSE students in this study, who spoke of their previous classroom experience as typically focused on listening to teachers and following text books; where the teacher was the centre of attention and classroom work was essentially an individualistic learning experience that was exam-orientated and competitive. All OSE students interviewed spoke of the contrast between their previous classroom culture and the PBL obligations listed above.

The focus on listening does not have a significant presence in the PBL literature and it appears that PBL students and tutors gave credit to speaking rather than listening as collaborative acts. OSE students' silence in PBL has not previously been identified as collaborative, and students themselves did not appear to value the contribution of their own listening practices. Educators need to be more sensitive to both listening and speaking and to scaffold students' skills, understanding and use of these different modes of collaborative practice.

\section{CLASSROOM PRACTICE IN THE HOME CULTURE}

The story we are trying to tell in this paper concerns the evident tensions between the classroom practices that overseas students bring with them to a new educational setting and the local norms of practice. In particular, we have presented the Silent Participant as a powerful example of the consequences of the mismatch between Asian and Western educational settings. In order to understand more fully the educational expectations that overseas students (and particularly students from Asian backgrounds) bring to the Western classroom, we will now present the results of research into the practices of classrooms in some of the home cultures of the students discussed earlier.

What Brousseau (1986) has brought to our attention is the reciprocality of the construction of classroom practice. Students engage in practices that afford and constrain teacher actions, and the actions of their classmates. These actions are undertaken in a culturally-grounded environment.

Social interaction by an individual within the classroom presumes that the individual has a model of the other classroom participants and can, to some extent, anticipate their capabilities, their needs, their expectations and their responses. This ability to anticipate the actions of others becomes extremely difficult in an unfamiliar culture. What is clear is the extent to which classroom practice is a jointly constituted body of negotiative social interactions that is best investigated and understood in terms of the mutuality and reciprocality of its constituent activities and of its co-construction as teaching/learning (Clarke, 2001).

In any classroom, participants subscribe to norms of practice that are the result of the group's collective social negotiation and which represent in their combination, the teacher's aspirations and expectations, the students' perceived rights and responsibilities, and the constraints imposed by the encompassing culture interpreted through local convention. In the following sections, analyses will be reported that suggest that these norms of classroom practice are very differently conceived and performed in the home cultures of some of the students represented in the earlier discussion of PBL participation in Melbourne.

\section{Kikan-Shido: A classroom pattern of participation}

Empirically, the integration of teaching and learning has been addressed in analyses of patterns of participation in mathematics classrooms in a variety of countries as part of the learner's perspective study (LPS). In particular, the classroom practice, designated elsewhere by the Japanese term kikan-shido (or between-desks-instruction), has provided a powerful example of a 'whole class pattern of participation' (Clarke, 2004). Our purpose in selecting kikan-shido for special attention is because examination of this aspect of classroom practice serves to illustrate important differences in the ways that classroom norms of practice are conceived and performed in different cultures. Kikan-shido is particularly suitable to serve as an illustration, because it is during the process of kikan-shido, that the teacher most visibly displays the norms of practice governing teacher-student interactions and the implicit pedagogical principles on which such norms are founded.

Japanese teachers possess an extensive vocabulary with which to describe their practice. Among the large number of terms available to them is the term kikan-shido, which means 'between desks instruction' in which the teacher walks around the classroom, predominantly monitoring or guiding student activity, and may or may not speak or otherwise interact with the students. Our use of kikan-shido honours the existence in one language of an established term that succinctly encapsulates an activity that could only be described in English by an extended phrase or lengthy definition. The utilisation of such terms conforms to a tradition that has seen déjà $v u$ and schadenfreude assimilated into English usage for precisely the same reasons.

In making the claim that kikan-shido could be described as an example of a whole class pattern of participation, it was necessary to demonstrate that it had a recurrent form, recognisable to those participating in it. This is not to say that the meanings attributed to the activity by those participating in it were correspondent. Individuals can participate in a practice whilst being positioned differently within it, and whilst attributing different characteristics to the activity. That is, without 
being identical, the participants' descriptions of the activity make it clear that they are talking about essentially the same form, but they may attribute quite different functions to that form. The other essential element is the need to demonstrate that all participants can shape the particular body of practice signified by kikan-shido. That is, that the pattern of participation is co-constructed.

Without reproducing the argument in full here, any theory of classroom practice must conceive of the activities in the classroom as co-constructed. kikan-shido as it has been reported (Clarke, 2004; O'Keefe, Xu, \& Clarke, 2006) is clearly a dance done by teachers and students, where the steps are improvized according to need. The participants in the classroom, teacher and students, are complicit (coconspirators) in this improvisation. Any characterisation of classroom practice must encompass the complementary actions of teacher and students within a single integrative frame. Kikan-shido provides an excellent example of the sort of social practice that is highly reflective of the culture in which it is undertaken. As such, it offers a window onto the cultural character of classroom practice in the various educational sites in which it was studied. We will now use Kikan-shido as the focus of our characterisation of the norms of practice in classrooms situated in both Asian and Western cultures.

\section{The distribution of responsibility for knowledge generation}

A central theme of our earlier discussion of the differential participation in PBL tutorials of students from different cultural backgrounds related the expectation that every student should participate in tutorial discussion. This focuses on attention on those norms of practice related to student spoken contributions in educational settings. Further, it seems reasonable to locate the responsibility for knowledge generation in an educational setting with those who introduce into the classroom discourse new knowledge, in the form of new technical terms. The analyses that follow combine a focus on student spoken contribution with an analysis of which classroom participants make spoken use of the technical terms that represent the substantive curricular content being addressed.

There is a general assumption in most literature that classroom discourse encompasses any form of interaction that takes place in a classroom. Nevertheless, con to focus on either the teacher's talk (Wilson, 1999; Young \& Nguyen, 2002) or teacher-students' interactions in either whole class (e.g., Klaassen \& Lijinse, 1996; Seah, 2004) or mroup dith \& Peressini, 2001). There is value in further research group discussion (e.g., Knuth \& Peressini, 2001 . The rolions in generating knowledge in the classroom. By student-student inter-personal interactions we mean communication between individual students, usually as members of dyads or small groups, and for which the intended audience was neither the whole-class nor the teacher.

Clarke and Seah (2005) adopted a more integrated and comprehensive approach, by analysing both public interactions in the form of whole class discussion and interpersonal interactions that took place between teacher and student and between student and student during between-desk-instruction. Interpersonal student-student interactions available for analysis were restricted to a focus group of up to four students. While this approach did not allow all interactions that took place in the classroom to be studied, it provided an avenue to track the generation of knowledge that could occur in both the public and interpersonal domains.

Analysis was carried out on video and post-lesson interview data related to mathematics lessons in Hong Kong. Melbourne, Shanghai and San Diego. All teacher classroom utterances and all statements by focus students, together with post-lesson interviews with teacher and students were transcribed and translated into English. The classroom transcript of each lesson was scanned for terms or phrases that expressed, represented, illustrated or explained mathematical concepts or understandings. These terms or phrases were referred to as math-related terms. These might take the form of conventional mathematical terms such as gradient or everyday expressions such as slope or steepness.

The capacity of this analytical approach to distinguish between classrooms is most evident in a comparison of eighth-grade mathematics classrooms in Shanghai and Hong Kong, since both sets of classrooms could be described as being embedded in a Confucian-heritage culture. The style of teaching in both Shanghai schools analysed was such that the teachers generally provided the scaffold needed for students to reach the solution to the mathematical problems without telling them everything. Hence, one could find quite a few math-related terms, which the teacher had not taught, that were introduced by the students during public discussion. A particularly powerful example of this devolution of responsibility occurred when the teacher in SH2-L04 (Shanghai School 2, Lesson 4) drew the class's attention to an alternative method of solving simultaneous equations being used by a student which the teacher described as more elegant than the standard (textbook) method.

Students in the Hong Kong classes studied were generally not given the same opportunities to contribute during lessons, in comparison with classes in the other three cities studied (Shanghai, Melbourne and San Diego). The teachers generally stated very explicitly every step for solving the mathematical problems discussed. In other words, students were guided through the steps for each problem type with very little opportunity for original thought or input into class discussion. Where a new math-related term was introduced into whole class public discussion, this was either done by the teacher or by a student in response to very explicit prompting from the teacher. There were, however, math-related terms that occurred for the first time in interpersonal conversation between students, but were not subsequently voiced in the public arena.

As examples of Asian classroom practice, in several respects the Hong Kong and Shanghai lessons analysed displayed more extreme differences in practice than those evident from comparison of Asian and Western lessons. Within the sets of lessons analysed for each city, significant variation was evident from the perspective of the distribution of responsibility for knowledge generation. The practices of the classroom in Shanghai School 2 provided some powerful supporting evidence for the contention by Huang (2002) and Mok and Ko (2000) 
that the characterization of Confucian-heritage mathematics classrooms as teachercentred conceals important pedagogical characteristics related to the agency accorded to students; albeit an agency orchestrated and mediated by the teacher.

A unique teaching strategy consisting of both teacher's control and students' engagement in the learning process emerges in Chinese classrooms (Huang, 2002, p. 227). Our purpose in contrasting the analyses of Hong Kong and Shanghai mathematics classrooms is twofold: (i) The classrooms in both cities provided clear examples of high levels of teacher control over the classroom discourse - in both contexts, students would seldom speak publicly except at the invitation of the teacher; (ii) Despite this similarity, the practices of the teachers in the two contexts appeared to conform to different pedagogical principles - Shanghai teachers being much less interventionist and more inclined to devolve responsibility to students for the generation of new knowledge than was the case in Hong Kong. On the one hand, we would like to avoid the trap of representing all Asian classrooms as though they conformed to the same norms of practice. This is clearly not the case. However, despite quite extreme differences in pedagogy, these Hong Kong and Shanghai classrooms displayed common norms of practice with respect to the teacher control of classroom discourse. It is the degree of teacher orchestration of student spoken participation that seems to be a key element in the OSE students' feelings of dislocation in the Australian multi-cultural classroom.

Our purpose at this point is to avoid any appearance of subscribing to the prevalent dichotomisation of classrooms into teacher-centred and student-centred and the implicit denigration of teacher-centred practices that seems to inevitably follow such a categorisation. Once the distribution of responsibility for knowledge generation is adopted as the integrative analytical framework, the oppositional dichotomisation of teacher-centred and student-centred classrooms can be reconceived as reflecting complementary responsibilities present to varying degrees in all classrooms. The deconstruction of the teacher-centred / studentcentred dichotomy has specific consequences for teacher practice. In particular, one of the most contentious entailments of this dichotomy can be revisited; the legitimacy of teacher telling. We will just pursue this issue of telling because it offers some insight into the value system that underlies much of educational reform in Western educational systems such as those in Australia and the USA.

One common interpretation of the constructivist manifesto (i.e., that "knowledge is the result of a learner's activity rather than of the passive reception of information or instruction", von Glasersfeld, 1991, p. xiv) has been that it became no longer legitimate for teachers to tell students anything. This position is not a logical consequence of adherence to constructivist learning theory, which suggests that students inevitably construct their own mathematics, whatever the classroom situation (Cobb, 1995). However, telling or not-telling have been constructed oppositionally with such success that publications on contemporary pedagogy (such as Wood, Nelson, \& Warfield, 2001), while usefully discussing many pedagogical strategies, see no need to address any strategies that might be construed as analogous to telling and even articles that purport to address the issue (such as Chazan \& Ball, 1999) offer teachers little insight into how (and, as importantly, when) their mathematical knowledge might be articulated explicitly to the benefit of their students.

Definitions of telling have been based on the form (i.e., whether or not the teacher is making a declarative statement or other type of assertion) rather than on the function of the teacher's action. A teacher's communicative act must be addressed from the related perspectives of the teacher's intention, the nature of the act, and the interpretations of the act by the recipients or audience. By focusing on function (intention, action, and interpretation) rather than form, we overcome some of the difficulties experienced in analyzing the efficacy of teacher practices from a constructivist perspective. Constructivist learning theory has been extrapolated to the domain of teaching practice, and constructivist teaching has been set up in opposition to transmissive teaching. Criticism of transmissive teaching has an extensive history and has sometimes led to simplistic exhortations to avoid telling without serious discussion of those teaching actions that involve directly introducing new ideas.

\section{Elicitation and initiation: A signature difference in practice}

Clarke and Lobato (2002) (and subsequently Lobato, Clarke, \& Ellis, 2005) have proposed a theoretical reformulation of teachers' communicative acts in terms of function rather than form. This reformulation is founded on the distinction between eliciting and initiating. By focusing on function (intention, action, and interpretation) rather than form, some of the difficulties experienced in analysing the efficacy of teacher practices from a constructivist perspective are overcome. Such a framework offers a more incisive tool for the analysis of the teacher's contribution to classroom discourse. In particular, it offers a language in which to frame the devolution of the responsibility for knowledge generation from the teacher to the student, or, alternatively, the concentration of that responsibility in the teacher. For example, teacher acts that take the form of a question but have the function of telling can be identified and the responsibility for the initiation of a new mathematical idea can be correctly located with the teacher rather than the responding student. Equally, as has been argued above, the capacity of the student to contribute to the generation of knowledge can be recognized, and classrooms can be compared according to the extent to which the student is accorded the opportunity to make this contribution. The fundamental consideration is the distribution of responsibility for knowledge generation.

Clarke and Lobato (2002) asserted the importance of interweaving the two functions initiating and eliciting. Since it is the development of the students' mathematics that we aspire to promote, it is the students' mathematics that takes priority. It is our contention, however, that the teacher's mathematics can also find legitimate voice in the classroom in the interest of stimulating the development of the student's mathematics. Initiating/eliciting is not a simplistic dichotomy like tell not tell - it's not an either / or. Both categories of action are necessary and their use is interrelated. Eliciting has typically been defined in terms of the form of the 
communicative act (e.g., asking questions such as 'Could you explain your reasoning?') or in terms of the degree of student involvement (e.g., the use of student-centred activities). Elicitation occurs when the teacher wants to learn more about students' images, ideas, strategies, conjectures, conceptions, and ways of viewing mathematical situations. When the teacher's communicative act functions to facilitate the expression of the student's mathematics, then this constitutes eliciting. In order to provide experiences that might challenge students to reorganize their thinking, teachers need to develop models of their students' mathematical realities (Simon, 1995; Steffe \& Thompson, 2000). The adequacy of these models will depend on the teacher's ability to elicit the student's mathematics.

Initiating is most profitably used in conjunction with eliciting. Elicitation occurs when the teacher wants to learn more about students' images, ideas, strategies, conjectures, conceptions, and ways of viewing mathematical situations. Initiating is often preceded by eliciting, so that the teacher can gather information about students' thinking before making a judgment whether to work with and structure the students' ideas or to introduce new information. Initiating involves the insertion of new ideas into the conversation, ideas that the teacher assumes will be interpreted in many different ways rather than passively received. Once the teacher engages in initiation, she then steps back and elicits to see what the students did with that information. Both actions have their function within the teacher's promotion of student conceptual development. The mutuality and complicit nature of these interactions bring us back to the spider's web, the epistemic student, and the co-constructed nature of teaching/learning. The agenda that frames such classroom activity is initially the teacher's agenda, but this agenda is iteratively modified in response to the progress of the ensuing classroom discussion in order to accommodate the students' prior and emerging understandings (see Lobato et al., 2005, for specific examples).

Where do we see the purposeful alternation of elicitation and initiation most clearly? One example can be found in the classroom in Shanghai, already referred to above. Unlike an Australian classroom, the students in this classroom rarely ever talked directly to each other - classroom conversation was always mediated by the teacher - yet the students were clearly learning most effectively. Part of the explanation came in the interview after the lesson. The teacher said: 'Don't teach them mechanically, don't teach them mechanically, let them brainstorm, enhance their flexibility.' And, 'I was not afraid that students had all sorts of questions. I just let them appear... Sometimes if you restrict them from doing this or that, their problems won't appear, right? But the problems will appear tomorrow, even if they didn't today, right?'

This is an articulate summary of the heart of the contemporary reform agenda in Western education and demonstrates a commitment to the purposeful elicitation of the students' mathematics. But, for cultural reasons, the opportunities for student discussion of the content were provided in a teacher-led whole class approach. With regard to the value attached to the students' mathematics, once elicited, in the lesson referred to earlier, this same teacher said to the class, 'Look at Shiqi's solution! This is much better than the usual method. Everyone copy this down.' As was evident in the analysis of the distribution of responsibility for knowledge generation in this classroom, the responsibility was shared between teacher and students and, in so far as the teacher's intentions could be put into effect, the classroom discourse was a purposeful alternation of initiation and elicitation.

It is in this manner that the utilisation of the distribution of responsibility for knowledge generation provides an integrative, explanatory framework that problematizes teacher-centred and student-centred characterisations of the classroom and resolves the false opposition of dichotomous practices by replacing them with a conception of alternative interrelated (and fundamentally complementary) classroom practices. It is this new analytical perspective that allows us to recognize and document revealing differences between so-called $A$ sian Classrooms located in different cultures. This same approach assists us in identifying distinctive features of classroom practice in the various settings studied and to reflect on the consequences for a students' learning of being accustomed to a very direct, interventionist style of teaching (e.g. Hong Kong) or a style in which student opinion was sought and valued, but only at the invitation of the teacher (Shanghai), or a style in which extremely fine-grained, narrowly-focused, incremental directions are given on targeted procedural skills (Singapore).

All three backgrounds were present across the set of PBL tutorial groups documented earlier in this paper. Despite quite profound differences in the underlying pedagogies in these three cultures, student expectations in all three cases were that student spoken contribution in class would only occur at the invitation of the teacher. The students' varied responses to PBL are more easily understood once the diversity in their educational experiences can be taken into account.

\section{MATOME: BRINGING IT ALL TOGETHER}

In their lesson planning, Japanese teachers prioritize summing up or bringing it all together (a lesson event they call Matome). In this part of the lesson, the teacher commonly invites selected students to share their work with the class as a catalyst to whole class discussion. We will draw selectively on some of the points made throughout this paper to make several points:

1. Students undertaking PBL in an educational environment that is culturally distant from their own will inevitably experience a sense of dislocation;

2. In the process of becoming enculturated into the local norms of classroom practice, a student may misread the cultural context and either not meet their obligations within the new setting or engage in inappropriate activities;

3. The student may also implement practices that were appropriate and even valued in their previous learning environment, but which are either not valued or misinterpreted in the new one (adoption of the role of Silent Participant would fall into this category);

4. International comparative research can provide the means to interrogate our 
most fundamental assumptions - in this case concerning some basic dichotomies that have pervaded our theorizing about classroom practice and learning;

5. Such dichotomies can be reconceived as complementary elements within more integrative theoretical frameworks, and thereby provide insights into the origins of the practices of overseas students (and their fundamental rationality);

6. The enactment of the student or teacher centered classroom is a window into the classroom culture in operation and the new comer needs to develop the cultural literacy needed to unpack how best to respond to the obligations of the classroom culture;

7. The devolution of responsibility for knowledge generation from teacher to student that is such a feature of PBL can also be found in classrooms in which teacher control is much more evident; and

8. A re-evaluation of the suitability and value of practices originating in other educational contexts may lead to their adaptation for use in multi-cultural classrooms; or, at least,

9. The recognition that OSE student adjustment to unfamiliar norms of practice might be supported more effectively based on an understanding of the practices of their home classrooms.

In order for international research to support the interrogation of the sort of fundamental educational assumptions outlined above, we must be sensitive to issues of cultural authorship: of representation and of voice. In commenting on the proliferation of OECD-initiated international comparative research projects, Cohen characterized the OECD as 'a club of 29 of the world's richest countries' (Cohen, 1998, p. 4). Even when less affluent countries participate in international studies, it is frequently as the objects of investigation rather than as partners in the research. As a consequence, research is frequently conducted from a Western perspective and evaluates the practices it studies by Western criteria. A notable and most welcome exception is the recent insider's perspective on Chinese mathematics teaching and learning (Fan, Wong, Cai, \& Li, 2004). Once we have achieved more equitable representation of all interested nations in international research programs, we need to ensure that the perspectives of all participating cultures inform the design and analytical frameworks employed, and that the voices of all participating cultures are evident in the reports that arise from such research.

The detailed collaborative study of international policy and practice in education, and of the products of that policy and practice, should be undertaken in anticipation of insights into the novel, interesting and adaptable practices employed in other school systems and of insights into the strange, invisible, and unquestioned routines and rituals of our own school system and our own classrooms.

One important manifestation of cultural authorship is the situatedness of our advocacy of any particular classroom practice. Hatano and Inagaki (1998) remind us that the adaptation of pedagogical practice requires consideration of both the practicality of technical implementation and the extent to which the beliefs underlying the adapted practice are in harmony with local cultural values. Fuller and Clarke (1994) made a related point:

The next generation of [research] questions pertains to how these tools are culturally situated and understood in the eyes of teachers and pupils, including how these tools help to structure the classroom's social rules. (Fuller \& Clarke, 1994, p. 144)

The cultural positioning of pedagogical practice is an essential precursor to its adaptation and application in other settings.

Oppositional dichotomies such as teacher-centred versus student-centred classrooms and telling versus not-telling offer educators false choices, sanctifying one alternative while demonizing the other. International research offers insight into possible explanatory frameworks within which such choices are no longer oppositional or even dichotomous, but rather can be seen as reflecting strategic and interrelated pedagogical decisions, dependent on purpose and context, that must be understood in cultural terms before they can be related to any setting outside their classroom of origin.

The reconstruction of these dichotomies as complementarities brings with it an obligation to review and revise the pedagogies and the pedagogical critiques previously predicated on the old dichotomous views. Among the consequences of such a re-viewing is the reassessment of the patterns of participation engaged in by students from cultures other than the one in which they are presently studying. The significance of the reviewing has been examined for the case of the Asian learner in the PBL classroom. In particular, the adoption of the role of Silent Participant has been examined in relation to its cultural origins, its underlying rationale, and its implications for the enactment of small group learning.

\section{REFERENCES}

Adams, G., \& Markus, H. (200I). Culture as patterns: An alternative approach to the problem of reification Culture and Psychology. 7(3), 283-296

Amos, E., \& White, M. J. (1998). Problem-based learning. Nurse Educator, 23(2), 11-14

Au, C., \& Enthwistle, N. (1999). 'Memorisation with understanding' in approaches to studying. Cultural variant or response to assessment demands? Paper presented at the European Association for Research on Learning and Instruction Conference, Gothenburg, August. Document added to Education-line database 16 May 2001

Azer, S A. (2001). Problem-based learning. Saudi Medical Journal, 22(5), 389-397.

Ballard, B. (1995). Some issues in teaching international students. In L. C. L.-A. Phillips (Ed.). Reaching more students. Queensland: Griffiths University.

Bennett, M. J. (1998). Intercultural communication: A current perspective. In M. J. Bennett (Ed.), Basic concepts of intercultural communication: Selected readings ( $\mathrm{pp}$ 1-34.). Yarmouth. Maine: Intercultural Press.

Blue, A. V., Stratton, T. D., Donnelly, M. B., Nash, P. P., \& Schwartz, R. W (1998). Student's communication apprehension and its effect on PBL, perfonnance. Medical Teacher, 20(3), 217-221

Brislin, R., \& Yoshida, T. (1993). Intercultural communication training: An introduction. Thousand Oaks, CA: Sage. 
Brousseau, G. (1986). Fondements et methodes de la didactique des mathematiques. Recherches en didactique des mathematiques. 7(2), 33-115

Burns. R. B. (1991). Study and stress among first year overseas students in an Australian university Higher Education Research and Development, 10(1), 61-77.

Chalmers. D. \& Volet, S. (1997). Common misconceptions about students from south-east Asia studying in Australia. Higher Education Research and Development, 16(I), 87-98

Chang, H.C. \& Holt. G. R. (1993). The concept of Yuan and Chinese interpersonal relationships In S T. - T. F. Korzenny (Ed.). Cross-cultural interpersonal communication (pp. 28-57) Newbury Park CA: Sage Publications

Chazan, D. \& Ball. D. (1999). Beyond being told not to tell. For the Learning of Mathematics, 19(2) 2-10.

Clarke, D. I. (1998). Studying the classroom negotiation of meaning: Complementary accounts methodology. In A. Teppo (Ed), Qualitative research methods in mathematics education (Monograph Number 9 of the Journal for Research in Mathematics Education, pp. 98-111). Reston. VA NCTM

Clarke, D. J. (Ed.) (2001). Perspectives on practice and meaning in mathematics and science classrooms Dordrecht: Kluwer Academic Press

Clarke, D. J. (2004). Patterns of participation in the mathematics classroom. In M. J. Hoines. \& A. B Fuglestad (Eds ). Proceedings of the 28th Conference of the International Group for the Psychology of Mathematics Education (vol. 2, pp 231-238). Bergen: PME.

Clarke, D. J., Emanuelsson, J., Jablonka, E., \& Mok, I. A. C. (Eds.) (2006). Making connections. Comparing mathematics classrooms around the world. Rotterdam: Sense Publishers

Clarke, D. J. \& Lobato, J. (2002). To tell or not to tell: A reformulation of telling and the development of an initiating/eliciting model of teaching. In C. Malcolm, \& C. Lubisi (Eds.), Proceedings of the tenth annual meeting of the Southern African Association for Research in Mathematics. Science and Technololgy Education (pp. 15-22). Durban: University of Natal

Clarke, D. J. \& Seah, L. H. (2005). Studying the distribution of responsibility for the generation of knowledge in mathematics classrooms in Hong Kong. Melbourne, San Diego and Shanghai $\ln \mathrm{H}$ L Chick, \& J. L. Vincent (Eds.). Proceedings of the 29th Conference of the International Group for the Psychology of Mathematics Education (vol. 2, pp. 257-264). Bergen: PME.

Cobb. P (1995). Continuing the conversation: A response to Smith. Edicational Researcher, 24(7), 25 27.

Cohen, D. (1998). World league tables: What's the score' Principal Matters, 10(1), 3-7

Dixon, A.. Lam. C., Lam, T., \& Ho, R. (1997). Can Hong Kong students cope with problem based learning. In J Conway, R. Fisher, L., Sheridan-Burns, \& G. Ryan (Eds), Research and development in problem-based learning (vol. 4, pp. 119-126). Newcastle: The Australian Problemdevelopment in problem-base

Dadkhah, A., Harizuka, S., \& Mandal, M. H. (1999). Pattern of social interaction in societies of the Asia-Pacific region. The Journal of Social Psychology, 139(6), 730-733.

Edens. K. M. (2000). Preparing problem solvers for the 21 st century through problem-based learning College Teaching, 48(2), 55-70

Eisenchlas, S A.. \& Trevaskes, S. (2003). Teaching intercultural communication in the university setting An Australian perspective. Intercultural Education, 1.14), 397-408

Eisenhart. M. (2001). Changing conceptions of culture and ethnographic methodologies Recent thematic shifts and their implications for research on teaching. In V. Richardson (Ed), Handbook of research on reaching (4th ed) (pp. 209-225). Washington, DC: AERA.

Fan, L., Wong, N-Y, Cai, J., \& Li S. (Eds.) (2004). How Chinese learn mathematics: Perspectives from insiders. Singapore: World Scientific Publishing

Forte. J. A. (1999) Culture: The tool-kit metaphor and multicultural social work. Families in Society The Joumal of Contemporary Human Services, $80(1), 51-77$

Fuller, B., \& Clarke, P. (1994). Raising school effects while ignoring culture? Local conditions and the influence of classroom tools. rules, and pedagogy. Review of Educational Research, $6+(1), 119-157$
Gamer. B. (1992). Southeast Asian Culture and Classroom culture. College Teaching. 37(4). 127-130 Geertz. C. (1973). The interpretation of culture. New York: Basic Books

Graham. C. L. (1996) Conceptual learning process in physical therapy students. Physical Therapy. $76(8), 856-866$

Greeno. J. G. (1997). On claims that answer the wrong questions. Educational Researcher. 26(1), 5-17

Gudykunst. W. B.. Ting-Toomey, S., \& Chua, E. (1988). Culture and interpersonal communication (vol. 8) Newbury Park Sage Publications

Gudykunst. W. B (1997) Cultural variability in communication. Communication Research. 2.f(4). 327 . 339

Gupta. K. (200I). How effective and culturally safe is learning in groups in a class-room environment' Paper presented at the Teaching and Learning Conference. July 9-12. Darwin

Hall, E. (1989). High and low context messages. The dance of life: The other dimension of ume (pp. 5977) New York: Doubleday

Hall, E., \& Hall. M. (1990) Culture is communication. Understanding cultural differences (pp. 3-31). Yarmouth: Intercultural Press

Harris, K. L., \& Nibler. R. (1998). Decision making by Chinese and U S students. The Journal of Social Psichology. 138(11). 102-114

Hatano, G., \& Inagaki, K. (1998). Cultural contexts of schooling revisited A review of the learning gap from a cultural psychology perspective. In S G. Paris, \& H. M. Wellman (Eds.), Global prospects for education: Development. culture and schooling (pp. 79-104). Washington, DC: American Psychological Association

Hermans, H. J. M. (2001). The dialogical self: Toward a theory of personal and cultural positioning. Culture Psychologv, 7, 243-281

Ho, D. Y.-F. (1993). Relational orientation in Asian social psychology. In U Kim \& J. W. Berry (Eds). Indigenous psychologies: Research and experience in cultural context (pp. 240-259). Newbury Park: CA: Sage.

Ho, D. Y. F. (1995). Selthood and identity in Confucianism. Taoism. Buddhism and Hinduism: Contrasts with the west. Journal for the Theory of Social Behaviour. 25(2). 115-138

Ho. D. Y -F (1998). Indigenous psychologies: Aslan perspectives Journal of Cross-Cultural Psychology, 29(1), 88-103.

Hofstede, G. (1986). Cultural differences in teaching and learning. International Journal of Intercultural Relations. 10, 301-320.

Hofstede. G. (1994). Cultures and organizations: Software of the mind. Intercultural cooperation and it importance for survival. London: Harper Collins Publishers.

Huang R. (2002). Mathematics teaching in Hong Kong and Shanghai: A classroom analysis from the perspective of variation. Unpublished Ph.D. thesis. Hong Kong: The University of Hong Kong.

Jones. A. (1999). The Asian learner: An ovenview of approaches to learning. Melbourne: Teaching and Learning Unit. University of Melbourne.

Kennedy, P. (2002). Learning cultures and learning styles: Myth-understandings about adult (Hong Kong) Chinese learners. International Journal of Lifelong Education. 2/(5). 430-445

Khoo, H. E. (2003). Implementation of problem-based learning in Asian medical schools and students' perception of their experience Medical Education, 37, 401-409.

Klaassen, C. W J M., \& Lijnse, P. L. (1996). Interpreting students' and teachers' discourse in science classes: An underestimated problem" Journal of Research in Science Teaching. 33(2), 115-134.

Knuth. E., \& Peressini, D. (2001). Unpacking the nature of discourse in mathematics. Mathematic Teaching in the Middle School, 6(5), 320-325.

Lave. I., \& Wenger. E. (1991) Situated learning: Legitimate peripheral participation. Cambridge: Cambridge University Press

Leung. F. K. S. (2001). In search of an East Asian identity in mathematics education. Educational Situdies in Mathematics. 17, 35-51

Li, D. (2007). The nature of Chinese students' out-of-class groupwork in two Australian Universities Unpublished Masters thesis. Melbourne: University of Melbourne. 
Lobato. J., Clarke. D. J, \& Ellis, A. B. (2005). Initiating and eliciting in teaching A reformulation of telling. Journal for Research in Mathematics Education, 36(2), 101-136

Miller. J. (1999). Becoming audible: Social identity and second language use. Journal of Intercultural Sizudies, 20(2). 149-160.

Minas. H. I. \& \& Klimidis, S. (1994). Cultural issues in posttraumatic stress disorder. In R. Watts, \& D. J de L Horne (Eds.). Coping with trauma: The victim and the helper (pp. 137-154) Brisbane Australian Academic Press

Mok. I. A C. \& Ko. P Y (2000) Beyond labels Teacher-centred and pupil-centred activities. In B Adamson. T. Kwan. \& K. K. Chan (Eds.). Changing the curriculum: The impact of reform on primary schooling in Hong Kong (pp. 175-194). Hong Kong: Hong Kong University Press.

Nisbett. R. E. Peng. K.. Choi, 1. \& Norenzayan, A (2001). Culture and systems of thought: Holistic vs analytic cognition. Psychological Review. 108. 291-310.

Nickson. M. (1992). The culture of the mathematics classroom: An unknown quantity. In D. A. Grows (Ed.). Handbook of research on mathematics reaching and learning (pp. 101-114) New York MacMillan Publishing Company

Niles, S. (1998). Achievement goals and means: A cultural comparison. Journal of Cross-Cultural Psychology. 29(5). 656-668.

Ninnes, P. Aitchison, C. \& Kolas. S. (1999). Challenges to stereotypes of international students prior experience: Undergraduate education in India. Higher Education Research and Development. $18(3)$. 323-341

Norenzayan. A., Nisbett, R. E. Smith. E., E., \& Kim. B. J. (2002). Cultural preferences for formal versus intuitive reasoning. Cognitive Science, 26(5), 653-684

O'Brien. L.. M. (1993). Teacher values and classroom culture: Teaching and learning in a rural. Appalachian head start program. Early Education and Development, $f(1), 5-19$

O'Keefe, C., Xu, L. H., \& Clarke, D. J. (2006). Kikan-Shido: Through the lens of guiding student activity. In J. Novotna. H. Moraova, M. Kratka. \& N. Stehlikova (巨.ds), Mathematics in the centre Proceedings of the Anmual Conference of the International Group for Psychology in Mathematics (vol. 4. pp. 265-272). Prague: PME

Peng. K. \& Nisbett. R. E. (1999). Culture, dialectics and reasoning about contradiction. American Psychologist. 54. 741-754.

Ramburuth, P. (2001) Cross cultural learning behaviour in higher education: Perceptions versus practice. ultiBASEarticles Melbourne: RMIT. [On line http://lultibase.rmie.edu.au/artciles/may $1 /$ ramburuth. I.htm]

Remedios, L., Clarke, D J.. \& Hawthorne, L. (2008). Framing collaboratıve behaviours: Listening and speaking in problem-based learning Interdisciplinany Journal of Problem-Based Learning. 2(1). 20

Samuelowicz. K. (1987). Learning problems of overseas students: Two sides of a story. Higher Education Research and Development, 6.121-134.

Schirato, A . \& Yell, S. (2000). Communication and cultural literacy: An introduction St Leonards. NSW Allen and Unwin.

Seah, L. H. (2004). A Cross-disciplinary approach to analysing a secondary school science lesson in Singapore. MEd Thesis. Melbourne: The University of Melbourne.

Spack, R. (1997). The rhetorical construction of multilingual students. The Forum. TESOL Quarterly. 3/(4. Winter), 765-774

Simon, M. (1995). Reconstructing mathematics pedagogy from a constructivist perspective. Journal for Research in Mathematics Edication, 26(2), 114-145.

Steffe, L. P.. \& Thompson, P W. (2000). Teaching experiment methodology. Underlying principles and essential elements. In A. E. Kelly, \& R. A. Lesh (Eds.). Handbook of research design in mathematics and science education (pp. 267-306). Mahwah: NJ: Lawrence Erlbaum

Ting-Toomey, S. (1999) Communicating across cultures. New York: Guilford Press.

Van Langenberghe. H V K (1988). Evaluation of student's approaches to studying in a problem-based physical therapy curriculum Physical Therapy, 68(4), 522-527. von Glasersfeld. E. (Ed) (1991) Radical constructivism in mathematics education Dordrecht. the Netherlands: Kluwer.

Wenger. E. (1998). Communities of practice: Learning. meaning. and identity Cambridge: Cambridge Unıversity Press

Wilson. J. M. (1999). Using words about thinking: Content analyses of Chemıstry teachers" classroom talk. International Journal of Science Education. $2 /(10), 1067-1084$

Wong. N-Y (2004) Mathematics education and culture: The " $\mathrm{CHC}$ " learner phenomenon l'erspectives from insiders. 503-534. [On line https//dspace lib cuhk/handle/2006/203958]

Wood. T, Nelson. B S .\& Wartield. J. (Eds ) (2001). Beyond classical pedagogv: Teaching elementary school mathematics. Mahwah. N.I: Lawrence Erlbaum

Young. R. F . \& Nguyen. II. T. (2002) Modes of meanıng in high school science. Applied Linguistics. $23(3) .348-372$

\section{AFFILIATIONS}

Louisa Remedios

University of Melbourne

Australia

David Clarke

University of Melbourne

Australia 


\section{University Library}

\section{- M M N E R VA A gateway to Melbourne's research publications}

Minerva Access is the Institutional Repository of The University of Melbourne

Author/s:

Remedios, L;Clarke, D

Title:

CULTURAL ORIGINS OF PATTERNS OF PARTICIPATION IN MULTI-CULTURAL CLASSROOMS

Date:

2019-01-01

Citation:

Remedios, L. \& Clarke, D. (2019). CULTURAL ORIGINS OF PATTERNS OF PARTICIPATION IN MULTI-CULTURAL CLASSROOMS. Social Interactions in Multicultural Settings, (1), pp.297-328. Sense Publishers.

Persistent Link:

http://hdl.handle.net/11343/30565 